\title{
Factors That Influence Nurses' Work-Family Conflict, Job Satisfaction, and Intention to Leave in a Private Hospital in Turkey
}

\author{
Dilek Ekici ${ }^{*}$, Kamuran Cerit ${ }^{2}$, Tugba Mert ${ }^{3}$ \\ ${ }^{1}$ Nursing Department, Health Science Faculty, Gazi University, Ankara, Turkey \\ ${ }^{2}$ Nursing Department, Health Science Faculty, Süleyman Demirel University, Isparta, Turkey \\ ${ }^{3}$ TOBB ETU Hospital, Ankara, Turkey
}

*Corresponding Author: Dilek Ekici, Associate Professor, Ph.D., R.N., Nursing Department, Health Science Faculty, Gazi University, Besevler, Ankara, Turkey. Tel: 903122162623, Email: docdrdilekekici@gmail.com

Received April 28, 2017; Accepted August 11, 2017; Online Published August 26, 2017

\begin{abstract}
Background: Nurses who have difficulty balancing their family role and responsibilities because of intense work pressure tend to leave their current jobs to work in organizations which offer better working conditions, lower workloads, and more managerial support.

Objective: This study aimed to determine nurses' work-family conflict (WFC), job satisfaction, and intention to leave the job in a private hospital.

Methods: This descriptive study is based on a methodological and causal research design. The population of the study included 98 nurses working in a private hospital. The research model is tested with structural equation modelling (SEM).

Results: Nurses working changing shifts reported statistically higher levels of work-to-family conflict and workload than those consistently working daytime shifts. Managerial support and workload explained $48 \%$ of WFC. Work structure alone explained $44 \%$ of job satisfaction. Job satisfaction and WFC explained $17 \%$ of the variance in intention to leave.

Conclusion: Nurses who have difficulty balancing their family roles and responsibilities because of intense work pressure tend to leave their current jobs to work in organizations which offer better working conditions, lower workload, and more managerial support. The work structure of nurses should be reorganized in order to enhance nurses' job satisfaction.

Keywords: Nurses, Workload, Family Conflict, Job Satisfaction
\end{abstract}

\section{Background}

Nurses are considered to be the main workforce in the protection and promotion of health and improvement in an individual's health in case of illness; however, in recent years a shortage in nursing has become a concern. ${ }^{1}$ The literature indicates that nurses who have difficulty in balancing their work and family responsibilities and who are dissatisfied with their jobs leave the institution where they work. ${ }^{2,3}$ To stop the increase in nurse turnover rates in hospitals, it is essential to determine the factors that influence nurses' work-family conflict (WFC), job satisfaction, and intent to leave; the necessary precautions should be taken before this situation escalates.

\subsection{Work-Family Conflict}

WFC is a type of inter-role conflict resulting from pressures created by concurrent demands of work and family roles. ${ }^{4}$ WFC occurs when work demands restrain individuals from fulfilling responsibilities and roles related to family. Role demands are significant factors for WFC. For example, conflicts related to work roles result from the stress experienced because of work demands and expectations such as timelessness and, especially, work overload. Previous studies reported that employees experienced time-based WFC as they spent more time at work..$^{4-6}$

Previous studies have found a positive and strong relationship between WFC and work demands such as working hours, workload, and irregular working hours. ${ }^{5-8}$ In particular, employees who work changing shifts cannot attend activities related to their families, and this situation prevents them from fulfilling their familial roles and responsibilities. ${ }^{5,6}$ Support provided by the manager is another significant factor influencing WFC. Studies indicate that presence of managerial support decreases WFC considerably. ${ }^{6,9}, 10$ With managerial support of employees when needed, employees can balance their work and family roles more easily. 
1.2. Job Satisfaction and Intention to Leave

Job satisfaction is defined as "the pleasurable emotional state resulting from the appraisal of one's job as achieving or facilitating the achievement of one's job values." 11 Studies report that WFC negatively influences job satisfaction.-7,12-14 According to studies about nurses' job satisfaction, autonomy over nursing practices, involvement in the decision-making process of the institution, impartial evaluations and rewards, and opportunities for professional development are all influential factors. ${ }^{2,3,15}$

Two major outcomes of job dissatisfaction are absenteeism and quitting one's job. ${ }^{2,3,12}$ Since replacing an employee with a new one is an incremental cost, turnover is an undesired situation for organizations. The literature indicates that many factors may influence the reasons why nurses leave their jobs; specifically, job dissatisfaction, inadequate pay for the work done, overworking and nonflexible working hours, heavy workload, and WFC are reported to have important impacts. ${ }^{2,5,8,16}$ Nurses who are unhappy and disappointed with their institutions leave and start work in another hospital, causing an increase in turnover rates of institutions. Qualified staff leaving increases nursing costs and workloads in hospitals, thus negatively affecting the quality of patient care. ${ }^{17}$

\section{Objective}

This study purposed to determine nurses' WFC, job satisfaction, and intention to leave the job in a private hospital. Moreover, the factors explaining WFC, job satisfaction, and intent to leave were evaluated. Factors such as workload, shift work status, managerial support, motivation for the job, work demands, and support were explored.

\subsection{The Theoretical Model and Hypotheses}

Managerial support (mansup) and workload are independent variables affecting WFC. Work structure (workstrc), work environment (workenv), and working conditions (workcon) are independent variables explaining job satisfaction (sat). WFC (wfc) is a mediator variable explaining job satisfaction and intention to leave the job (intleave). Intention to leave the job is the dependent variable to be explained.

\section{Methods}

\subsection{Study Design and Samples}

This study utilized the causality and descriptive method. It attempted to explain causal relationships among nurses' workload, managerial support, WFC, working conditions, work environment, work structure, job satisfaction, intention to leave, and the factors influencing intention to leave by using structural equation modelling (SEM).

The population of the study included nurses who were working more than 45 hours and more than 5 days per week in private hospitals in Ankara, Turkey. Two hospitals were chosen by simple random sample from these hospitals. Written applications with the explanation of the study's purpose and method were submitted to the hospitals where the study was conducted. Permission for the study was received from only one hospital. After obtaining written permission from the institution, data collection was begun. Based on the aim of the study, the scope of the research comprised all nurses working in a private hospital. The population of the study included 101 nurses working in a private hospital in Ankara, Turkey which had 93 beds and a JCI (Joint Commission International) Quality Certificate. Nurses employed at this hospital work 9 hours per shift and 5 or 6 shifts per week. All nurses working in the hospital were asked to participate in the study without any sampling. Data was collected from the willing nurses who joined the research. Response rate was $97 \%$.

\subsection{Instruments}

A 5-section questionnaire was used to collect data. The first section questioned the participants' demographic characteristics.

In the second section, "shift work status" was assessed with the question "Do you work shifts?" Participants replied to this question with 1: No, I work during the daytime; or 2: Yes, I work shifts. In that section, the 11-item Individual Workload Perception Scale, developed by Duxbury and Higgins $^{18}$ and adapted to Turkish by Aycan and Eskin, ${ }^{19}$ was used to measure workload. The scale includes aspects of workload, flexibility, and control experiences. It includes items such as "I am overwhelmed by my responsibilities and workload" and "I have to work a lot and long hours." Participants answered on a 5-point Likert scale anchored with 1 (strongly disagree) and 5 (strongly agree). Higher scores indicated higher work demands and lower flexibility. Cronbach alpha coefficient for the scale was 0.80 in this study.

In the third section, the 10-item Supervisor Support Scale, developed by Galinsky et $\mathrm{al}^{20}$ and adapted to Turkish by Aycan and Eskin, ${ }^{19}$ was used. The scale items evaluated the support provided to employees in fulfilling their work and family responsibilities. It involved 2 types of support: emotional support which is a form of empathizing, and informal support which includes providing convenience and assisting the employee in meeting his/her family expectations including arranging working hours. The Supervisor Support Scale is also a 5-point Likert scale where 1 is never and 5 is always. Higher scores indicate higher levels of support. Cronbach alpha coefficient for this scale was 0.82 in this study.

In the fourth section, the 7-item Work-to-Family Conflict Scale developed by Netemeyer et $\mathrm{al}^{21}$ and adapted to Turkish by Aycan and Eskin ${ }^{19}$ was used to measure WFC. The scale is a 5-point Likert scale where 1 is strongly agree and 5 is strongly disagree. Higher scores indicate higher levels of conflict. Cronbach alpha coefficient for this scale was 0.83 in this study.

The fifth section included the factors influencing job satisfaction. After reviewing the relevant literature, economic, structural, and psychological factors influencing 
job satisfaction were selected..$^{2,5,8,16}$ The factors were categorized into three dimensions: (1) working conditions (job security, charges, working hours, leaves of absence, etc) with 6 items; (2) work environment (relationships with managers and co-workers, sufficient equipment, physical conditions like heating, etc) with 5 items; and (3) work structure (involvement in decision making, autonomy, opportunities for development and promotion, admiration, impartial evaluation and rewards, distribution of tasks, etc) with 7 items. The nurses were asked to indicate to what extent their expectations were met by the institution on a 7 -point scale ranging from 1 (minimum) to 7 (maximum). To determine the level of job satisfaction, one question was added to the scale. The participants were asked to rate their work according to their own values, ideals, and purposes from 0 (not at all satisfied) to 5 (satisfied) to 10 (absolutely satisfied). ${ }^{22}$ The nurses were also asked to rate their intention to leave from 0 (I definitely think about leaving my job) to 5 (I sometimes think about leaving my job) to 10 (I don't have any intention of leaving my job).

\subsection{Data Analysis}

Data was analyzed using LISREL 8.80 and SPSS 20.0 software programs. Mean scores obtained from the scales and standard deviations were calculated. To determine the differences between mean scores according to demographical data, independent-samples $t$ test, MannWhitney U test, one-way analysis of variance (ANOVA), and Kruskal-Wallis test were performed.

A 2-phase approach was adopted for the analysis of the model; thus the measurement model and structural model were tested separately. ${ }^{23}$ In the first phase, CFA was performed in LISREL to obtain parameter estimates of each scale and to determine the appropriate measurement model. In the second phase, analyses related to the structural model were performed by establishing the causal relationships in the proposed theoretical model. In this phase, after excluding the factors which were statistically insignificant and making the suggested corrections in LISREL, the final model explaining intention to leave was re-established. Critical $n$ value of the study was 94 . To evaluate model fit, chi-square $\left(\chi^{2}\right)$ /degree of freedom $(d f)$, adjusted goodness of fit index (AGFI), goodness of fit index (GFI), normed fit index (NFI), non-normed fit index (NNFI), comparative fit index (CFI), root-mean-square error of approximation (RMSEA), and standardized root mean square residuals (SRMR) were calculated. Cronbach alpha coefficients for reliability of the measurement tools were calculated in SPSS version 20.0.

\section{Results}

\subsection{Demographic Data}

Out of 98 participants, $83(88 \%)$ were clinical nurses and $11(12 \%)$ were head nurses and supervisor nurses. Forty participants (42\%) graduated from vocational high school and $55(58 \%)$ from university. While $78(82 \%)$ were nurses, 17 (18\%) were nurse-midwives. Twenty-six nurses (27\%) worked the daytime shift consistently, while 69 (73\%) worked changing shifts. The average duration of being present at hospital, which included rest periods, was 54 $( \pm 5.64)$ hours or more in a week. Thirty-eight $(40 \%)$ of the participants were married and their spouses were also working, and 26 (28\%) had children. The average age of the participants was $30.88( \pm 6.71)$ years, and the average duration of working at the job was $10.46( \pm 6.88)$ years.

While $32 \%$ of the nurses were dissatisfied with their job, $52 \%$ were moderately satisfied and $16 \%$ were satisfied. When intention to leave was analyzed, $46 \%$ of the participants were seriously contemplating leaving, 35\% thought about leaving from time to time, and 19\% did not intend to leave.

To analyze whether there was a difference between the nurses working during the daytime $(\mathrm{n}=26)$ and those working shifts $(n=69)$, the Mann-Whitney $U$ test was performed on WFC, workload, and managerial support. Workload $(\mathrm{z}=-2,66 ; P<0.01)$ and WFC $(\mathrm{z}=-1,71 ; P$ $<0.05)$ were higher among the nurses working shifts. Conversely, no difference was found in managerial support between the groups $(P>0.05)$.

\subsection{Structural Equation Model Results}

In the first phase of the two-phased approach used in this study, the measurement models with 6 factors (managerial support, workload, working conditions, work environment, work structure, and WFC) were validated using corrective measures so as to produce acceptable fit indices. Items which were statistically insignificant (with a $t$ value under 1.96) and error variances which were related to another item's error variance were excluded from the measurement models. The numbers of excluded items were as follows: 6 items from workload, 4 from managerial support, 2 from WFC, 1 from work structure, and 4 from working conditions. After identifying the appropriate measurement models, the second phase was begun in order to perform analyses related to the structural model. In that phase, the theoretical model was tested by establishing causality between the variables (Figure 1).

According to the results, the relationship between job satisfaction and the factors of work environment (H4: rejected) and working conditions (H5: rejected) were not statistically significant ( $t$ values, respectively: 0.60 , 1.19) (Figure 1). These factors were excluded in the final model. The relationship between WFC and job satisfaction (H6: rejected) was not statistically significant $(t=0.15)$ (Figure 1), so this relationship was not identified in the final model (Figure 2). Goodness-of-fit and correction indices were evaluated for the final model which was reestablished after revision. Items and error variances, which were correlated with each other, were determined in the correction indices. Correlation between errors violates the assumption that errors are independent in the SEM. ${ }^{24}$ For this reason, among items with correlated errors, 6 items, which had the largest contribution to the decrease of chisquare values, were excluded from the model ( 3 items from 


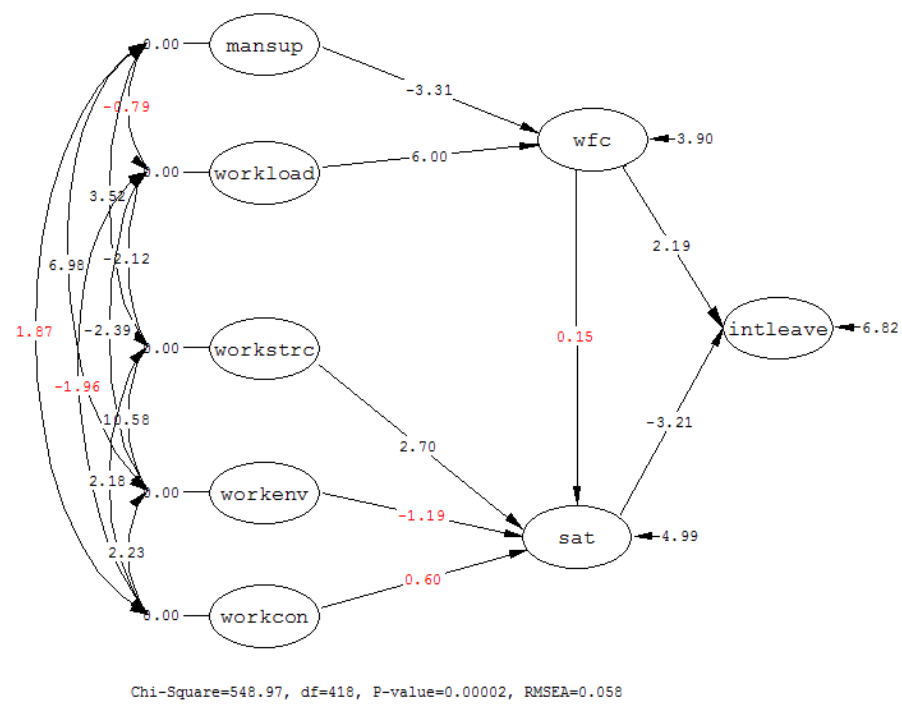

Figure 1. Testing the Structural Equation Modelling (SEM) and Theoretical Model: Correlations Between Factors and $t$ Values.

managerial support, 1 from workload, and 2 from work structure).

In the final model validated by SEM analysis, correlations between factors of the model and standardized coefficients (regression coefficients) of the items are shown in Figure 2. Goodness-of-fit indices of the validated model were as follows: $\chi^{2} / d f(137.11 / 127)$ was 1.08 (<2: good fit); RMSEA was 0.029 (good fit); SRMR was 0.076 (acceptable fit); GFI was 0.86 (poor fit); AGFI was 0.81 (poor fit); NFI was 0.90 (acceptable fit); NNFI was 0.98 (good fit); CFI was 0.98 (good fit). Structural equations of the model are presented in Table 1.

According to the analysis of structural equations, workload was the most influential factor for WFC, and a one-unit increase in workload was associated with a 0.58-unit increase in WFC. The managerial support factor influenced WFC negatively; a one-unit increase in managerial support caused a 0.25 -unit decrease in WFC.
These 2 factors together explained $47 \%$ of the variance in WFC.

Work structure influenced job satisfaction positively, and this factor alone explained $44 \%$ of job satisfaction. Job satisfaction had a negative impact on intention to leave; a one-unit increase in job satisfaction caused a 0.31-unit decrease in intention to leave. WFC influenced intention to leave positively; a one-unit increase in WFC caused a 0.24-unit increase in intention to leave. Job satisfaction and WFC together explained $17 \%$ of intention to leave. Cronbach alpha coefficients were 0.82 for managerial support; 0.80 for workload; 0.83 for WFC; and 0.722 for work structure (4 items).

\section{Discussion}

Studies have shown that, on one hand, nurses leave their jobs because of unfavorable working conditions and on the other, intention to leave increases among nurses who

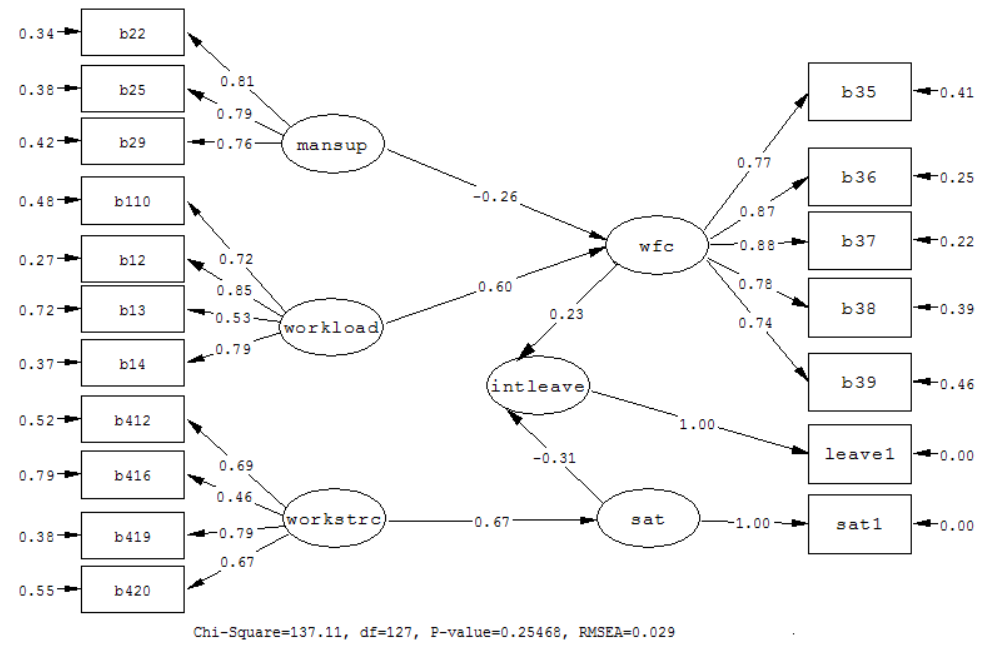

Figure 2. Standardized Loadings for the Final Model. 
Table 1. Structural Correlations and Equations for the Final Model

\begin{tabular}{llll}
\hline Structural Correlations & Standard Errors & $\mathbf{R}^{2}$ & Structural Equations \\
\hline Mansup + Workload $\rightarrow$ WFC & 0.48 & 0.47 & WFC $=-0.25$ mansup +0.58 workload \\
Workstrc $\rightarrow$ Sat & 0.56 & 0.44 & Sat $=+0.67$ workstrc \\
WFC + Sat $\rightarrow$ Intleave & 0.82 & 0.17 & Intleave $=+0.24$ wfC -0.31 sat \\
\hline
\end{tabular}

are overworked because of nursing shortages. This study purposed to determine the role of job satisfaction and WFC in explaining nurses' intentions to leave their jobs.

\subsection{Work-Family Conflict}

According to this study, the nurses working changing shifts reported statistically higher levels of WFC and workload than those consistently working during the daytime $(P<0.05)$. In the hospital where the study was conducted, nurses worked an average of $54( \pm 5.64) \mathrm{h} /$ wk. According to the literature, long working hours increase WFC. ${ }^{25}$ Long working hours, including nights and weekends, and the inability to participate in family activities prevent employees from fulfilling their familial roles and responsibilities. This situation shows us that nurses experience time-based WFC, as they waste more time at work due to shift working. Moreover, the large amount of work to be done during working hours and nursing shortages produce higher workloads for nurses. In this study, greater workloads were found to increase WFC. This finding supports the results of other studies. ${ }^{5-7,25,26}$

Another finding was that managerial support reduced WFC. According to the literature, the presence of managerial support considerably decreases WFC of employees. ${ }^{910,18,27}$ If a manager provides informal support (such as shift arrangements) when needed at work, employees balance their work and family roles more easily. However, managerial support is not specific to a job or profession; it is connected to organizational culture or the manager's personal attitudes and behaviors. ${ }^{14}$

\subsection{Job Satisfaction}

Job satisfaction occurs when employees' expectations from the job are met. It is the level of employees' contentment felt with not only the nature of the work, but also the opportunities provided to them. This study found that $32 \%$ of the participants were dissatisfied with their jobs, while $52 \%$ were moderately satisfied and $16 \%$ were satisfied. Aiken et $\mathrm{al}^{1}$ reported in their study that Japan had the highest rate of dissatisfied nurses (66\%), followed by China (55\%), South Korea (50\%), and the United Kingdom (42\%).

As stated in the literature, factors such as work environment and working conditions along with work structure have an impact on job satisfaction..$^{2,3,15,16,28}$ When the theoretical relations were tested in the current study, no significant correlation was observed between job satisfaction and the factors of work environment, work condition, and WFC, and these factors were excluded from the final model. Consequently, work structure was the only factor which explained job satisfaction, and it included items of autonomy, participation in decisions, distribution of tasks, impartial performance evaluation, and rewards. Furthermore, the items related to work structure were found to explain job satisfaction markedly (44\%).

Studies argue that factors such as autonomy and participation in decisions have significant influences on employees' job satisfaction..$^{3,16}$ Autonomy refers to the ability of professionals to make independent decisions about their subject areas and to implement their activities independently in accordance with these decisions. Autonomy also involves the authority to observe and evaluate the implementations without permission or confirmation from anyone. It is important for nurses to participate in decisions about their work and to have autonomy, in other words to be able to add their creativity into their work. Thus, nurses will be satisfied with their jobs if they can add their creativity into work instead of doing routine work.

Hughes et $\mathrm{al}^{29}$ stated that factors such as the lack of clear performance expectations, unclear distribution of tasks, and role ambiguity influence work performance and job satisfaction negatively. It is important to clarify the responsibilities that nurses should fulfill and to acknowledge their work. ${ }^{3,15}$ Employees who are not admired experience ambiguity about how their work is perceived. This ambiguity influences their job satisfaction negatively. Thus, to appreciate the achievements of nurses in return for their work and to give them rewards they deserve will influence nurses' job satisfaction positively. This argument is consistent with the current findings that showed factors concerning work structure, such as clear distribution of tasks, impartial performance evaluation, and rewards, had a significant impact on job satisfaction.

According to the results, $\mathrm{H} 6$ about the significant impact of WFC on job satisfaction was rejected. Relevant studies conducted in Australia, Canada, New Zealand, England, and the United States have demonstrated that WFC has an important effect on job satisfaction; however, those conducted in Asia and Latin America argue that it does not have an important effect. ${ }^{5,26,30}$ The different results are attributed to cultural differences; in individualistic societies like the United States, England, and Canada, WFC significantly impacts job satisfaction, whereas in collectivist societies like Asia, Turkey, and Latin America, it does not directly impact job satisfaction., ${ }^{5,1326}$ Job and life satisfaction are important for individuals in individualistic societies to feel good about themselves, because WFC directly affects job satisfaction. ${ }^{13}$ The WFC levels of nurses 
increase when they cannot get enough social support from their families. ${ }^{31}$ In Turkey, due to the collectivist family structure which includes social support from family, nurses are not thought to experience negative feelings about their jobs, even if they experience WFC.

\subsection{Intention to Leave}

The average age of participants in this study was 30.88 ( \pm 6.71 ) years, and $46 \%$ of them seriously intended to leave their jobs. In a study conducted in five countries (the United States, Canada, England, Scotland, and Germany) by Aiken et al, ${ }^{1}$ intention to leave rates of nurses under 30 years of age were $29 \%-54 \%$. In another study conducted in 10 European countries by Heinen et al, ${ }^{12}$ nurses working in Finland had the highest rate of intention to leave (49\%), followed by Ireland and the United Kingdom (44\%). In the current study, job satisfaction and WFC explained $17 \%$ of the nurses' intention to leave. According to the relevant studies, there is a correlation between job satisfaction and intention to leave, and those nurses with low job satisfaction seek to leave the institution as soon as possible. ${ }^{1-3,12,13}$ Furthermore, it is stated in the literature that experiencing WFC increases nurses' intention to leave their jobs ${ }^{27,31}$; however, nurses experiencing family-work conflict do not have intentions to leave their jobs. ${ }^{31}$ These results imply that nurses who have difficulty balancing their family role and responsibilities because of intense work pressure intend to leave their current job for work in another organization which offers better working conditions, lower workload, and more managerial support.

\section{Conclusion}

According to the analyses of theoretical correlations tested in this study, there was no correlation between job satisfaction and the factors of work environment, working conditions, or WFC; thus, these factors were excluded from the final model. Managerial support and workload explained $48 \%$ of WFC. Work structure alone explained $44 \%$ of job satisfaction. Job satisfaction and WFC explained $17 \%$ of the variance in intention to leave. Goodness of fit indices of the study model were calculated as follows: $\chi^{2} / d f$ $=1.08 ;$ RMSEA $=0.029 ;$ SRMR $=0.076 ; \mathrm{GFI}=0.86 ; \mathrm{AGFI}$ $=0.81 ; \mathrm{NFI}=0.90 ; \mathrm{NNFI}=0.98$; and $\mathrm{CFI}=0.98$. To sum up, the fit between the data and the theoretical model of measurement tool was good.

\section{Implication for Nursing Health Policy}

Today, the nursing shortage is an important problem. Thus, strategies to keep nurses in their current institutions should be developed by focusing on WFC and job satisfaction factors that impact leaving. Work structure was the only factor which explained job satisfaction, and it included items of autonomy, participation in decisions, distribution of tasks, impartial performance evaluation, and rewards. The work structure of nurses should be reorganized in order to enhance job satisfaction. While achieving this, it is beneficial to involve nurses in decisions about their
Research Highlights

\section{What Is Already Known?}

Nurses who have difficulty balancing their work and family responsibilities and who are dissatisfied with their jobs leave the institutions where they work. Employees' contentment is felt with not only the nature of the work, but also the opportunities provided to them.

\section{What This Study Adds?}

Work structure was the only factor which explained job satisfaction, and it included items of autonomy, participation in decisions, distribution of tasks, impartial performance evaluation, and rewards.

activities, distribute tasks clearly, and evaluate and reward performances impartially. Moreover, if managers support nurses in balancing WFC and lightening workload, the rate of intention to leave will be reduced. Consequently, these results will provide significant contributions both to the literature and to clinical work environments.

\section{Limitations}

One of the most important limitations of the current study is that the population for the study is from just one hospital. This limitation prevents generalizing the results. Still, $98 \%$ of nurses working in the hospital participated, illustrating how well the study represents the total population. Therefore, further studies with larger samples are recommended. In this study, $17 \%$ of the variance in the intention to leave was explained. Even if this rate is an important contribution to the literature, a major part of intention to leave was not explained. However, WFC and job satisfaction can be explained with higher rates (respectively, 47\% and 44\%). It is suggested that intention to leave from the job can be better explained in further studies by adding different variables to the model.

The study population came from a collectivist culture, so the results concerning WFC and job satisfaction are limited because of cultural differences. Thus, these results should be compared to samples from individualistic cultures.

\section{Authors' Contributions}

Study design: DE; Data collection: DE and TM; Data analysis: KC and DE; Study supervision: DE; Manuscript writing: $\mathrm{DE}$ and $\mathrm{KC}$; Critical revisions for important intellectual content: $\mathrm{DE}$ and $\mathrm{KC}$.

\section{Conflict of Interest Disclosures}

The authors declare no potential conflicts of interest with respect to the research, authorship, and/or publication of this article.

\section{Ethical Approval}

Oral consent was taken from the nurses after the study's purpose was explained. After being informed about data privacy, participants were asked not to write down their 
names and were advised to complete the surveys at their convenience. The participants were instructed to put their completed surveys in the box which was placed in the hospital. The anonymity of respondents was ensured.

\section{Acknowledgments}

The authors would like to express their sincere appreciation to the health professionals who participated in this study and to the experts for their opinions.

\section{References}

1. Aiken LH, Sloane DM, Clarke S, et al. Importance of work environments on hospital outcomes in nine countries. Int J Qual Health Care. 2011;23(4):357-364. doi:10.1093/intqhe/ mzr022.

2. Coomber B, Barriball KL. Impact of job satisfaction components on intent to leave and turnover for hospital-based nurses: a review of the research literature. Int J Nurs Stud. 2007;44(2):297-314. doi:10.1016/j.ijnurstu.2006.02.004.

3. Hayes LJ, O'Brien-Pallas L, Duffield C, et al. Nurse turnover: a literature review. Int J Nurs Stud. 2006;43(2):237-263. doi:10.1016/j.ijnurstu.2005.02.007.

4. Greenhaus JH, Beutell NJ. Sources of conflict between work and family roles. Acad Manage Rev. 1985;10(1):76-88. doi:10.2307/258214.

5. Anafarta N. The Relationship between work-family conflict and job satisfaction: a structural equation modeling (SEM) approach. International Journal of Business and Management. 2011;6(4):168-77. doi:10.5539/ijbm.v6n4p168.

6. Yildirim D, Aycan Z. Nurses' work demands and workfamily conflict: a questionnaire survey. Int J Nurs Stud. 2008;45(9):1366-1378. doi:10.1016/j.ijnurstu.2007.10.010.

7. Simunic A, Gregov L. Conflict between work and family roles and satisfaction among nurses in different shift systems in Croatia: a questionnaire survey. Arh Hig Rada Toksikol. 2012;63(2):189-197. doi:10.2478/10004-1254-63-20122159.

8. Patel CJ, Beekhan A, Paruk Z, Ramgoon S. Work-family conflict, job satisfaction and spousal support: an exploratory study of nurses' experience. Curationis. 2008;31(1):38-44. doi:10.4102/curationis.v31i1.906.

9. Anderson SE, Coffey BS, Byerly RT. Formal organizational initiatives and informal workplace practices: links to work-family conflict and job-related outcomes. J Manage. 2002;28(6):787-810. doi:10.1016/S0149-2063(02)00190-3.

10. Burke RJ, Greenglass ER. Work-family conflict, spouse support, and nursing staff well-being during organizational restructuring. J Occup Health Psychol. 1999;4(4):327-336. doi:10.1037/1076-8998.4.4.327.

11. Locke EA. What is Job Satisfaction? Organ Behav Hum Perf. 1969;4(4):309-336. doi:10.1016/0030-5073(69)90013-0.

12. Heinen MM, van Achterberg $T$, Schwendimann $R$, et al. Nurses' intention to leave their profession: a cross sectional observational study in 10 European countries. Int J Nurs Stud. 2013;50(2):174-184. doi:10.1016/j.ijnurstu.2012.09.019.

13. Spector PE, Allen TD, Poelmans SAY, et al. Cross-national differences in relationships of work demands, job satisfaction, and turnover intentions with work-family conflict. Pers Psychol. 2007;60(4):805-835. doi:10.1111/j.1744-6570.2007.00092.x.

14. Poelmans SA, ed. Work and family: an international research perspective. Mahwah NJ: Lawrence Erlbaum Associates; 2005.

15. Boles JS, Wood JA, Johnson J. Interrelationships of role conflict, role ambiguity, and work-family conflict with different facets of job satisfaction and the moderating effects of gender. Journal of Personal Selling \& Sales Management. 2003;23(2):99-113. doi: 10.1080/08853134.2003.10748991.

16. Lu H, While AE, Barriball KL. Job satisfaction among nurses: a literature review. Int J Nurs Stud. 2005;42(2):211-227. doi:10.1016/j.ijnurstu.2004.09.003.

17. Aiken LH, Clarke SP, Sloane DM, Lake ET, Cheney T. Effects of hospital care environment on patient mortality and nurse outcomes. J Nurs Adm. 2008;38(5):223-229. doi:10.1097/01. NNA.0000312773.42352.d7.

18. Duxbury L, Higgins C. Interference between work and family. Employee Assistance Quarterly. 1994;9(3-4):55-80. doi:10.1300/J022v09n03_05.

19. Aycan Z, Eskin M. Childcare, spousal, and organizational support in predicting work-family conflict for females and males in dual-earner families with preschool children. Sex Roles. 2005;53(7):453-471. doi:10.1007/s11199-005-7134-8.

20. Galinsky E, Bond JT, Friedman DE. The role of employers in addressing the needs of employed parents. J Soc Issues. 1996;52(3):111-136. doi:10.1111/j.1540-4560.1996. tb01582.x.

21. Netemeyer RG, Boles JS, McMurrian R. Development and validation of work-family conflict and family-work conflict scales. J Appl Psychol. 1996;81(4):400-410. doi:10.1037/00219010.81.4.400

22. Dolbier CL, Webster JA, McCalister KT, Mallon MW, Steinhardt MA. Reliability and validity of a single-item measure of job satisfaction. Am J Health Promot. 2005;19(3):194-198. doi:10.4278/0890-1171-19.3.194.

23. Loehlin JC. Latent Variable Models: An Introduction to Factor, Path, and Structural Analysis. 4th ed. Mahwah, NJ: Lawrence Erlbaum Associates; 2004.

24. Jöreskog KG, Sörbom D. LISREL 8: User's reference guide, scientific software international. North Lincoln Avenue, USA; 2004.

25. Amstad FT, Meier LL, Fasel U, Elfering A, Semmer NK. A metaanalysis of work-family conflict and various outcomes with a special emphasis on cross-domain versus matching-domain relations. J Occup Health Psychol. 2011;16(2):151-169. doi:10.1037/a0022170.

26. Jeffrey Hill E, Yang C, Hawkins AJ, Ferris M. A crosscultural test of the work-family interface in 48 countries. J Marriage Fam. 2004;66(5):1300-1316. doi:10.1111/j.00222445.2004.00094.x.

27. Blomme RJ, Van Rheede A, Tromp DM. Work-family conflict as a cause for turnover intentions in the hospitality industry. Tourism and Hospitality Research. 2010;10(4):269-285. doi:10.1057/thr.2010.15.

28. Zareifar S, Haghpanah S, Beigipour Z, Hosseini S, Molavi MA, Naderi M. Job satisfaction and stress levels of nurses working in oncology wards; a multicenter study. Galen Medical Journal. 2017;6(2):128-135.

29. Hughes RL, Ginnett RC, Curphy GJ. Leadership - Enhancing the Lessons of Experience. 4th ed. New York, USA: McGrawHill; 2002.

30. Brough P, Kalliath T. Work-family balance: theoretical and empirical advancements. J Organ Behav. 2009;30(5):581-585. doi:10.1002/job.618.

31. Van der Heijden BI, van Dam K, Hasselhorn HM. Intention to leave nursing: The importance of interpersonal work context, work-home interference, and job satisfaction beyond the effect of occupational commitment. Career Development International. 2009;14(7):616-635. doi:10.1108/13620430911005681. 